\title{
Micro Mechanical Force Sensor Application Situation and Expectation Analysis
}

\author{
Ding Hao, Zhu Jin, Qin Yuping, Zhang Shuang \\ The Engineering \& Technical College of Chengdu University of Technology \\ Leshan, china, 614000
}

\begin{abstract}
Sensor's microminiaturization is one of the important developing direction of the sensing technology. Micro mechanical processing technology is based technology of micro silicon sensor, and is also used to make micro actuators and microelectromechanical system technology, The appearance of micro mechanical processing technology puts forward sensor, especially force sensor, to a new development stage. This article will give a brief analysis focusing on some of the micro mechanical force sensor application situation and application prospects.
\end{abstract}

Keywords-Micro mechanical force, sensors, summarize

\section{INTRODUCTION}

Industrial equipment in the manufacturing process and test of overall performance is inseparable from the various mechanical and geometric quantities, some industrial equipment in operation often test or monitor to multiple volume, including displacement, speed, acceleration, force, torque, power, pressure, flow, temperature, hardness, density, humidity, specific gravity, viscosity, length, angle, shape, location, surface roughness, surface wave etc, which belongs to the physical quantity. The actual production, life and scientific experiments will also meet the chemical content, biomass ( including medical ), and all of this, from the point of signal engineering, all need to pass the sensor, converts them into electrical signals (Modern can also be converted into optical signals ), then for signal transmission, processing, storage, display, control ... ... , from the information perspective, these signals along with sound and image information are the source of information, so the sensor, detection instrument, and measuring instrument are important parts of the information science and technology three portion ( information acquisition, information transmission, information processing ).

Sensor's microminiaturization is one of the important developing directions of the sensing technology. Micro mechanical processing technology is based technology of micro silicon sensor, and is also used to make micro actuators and microelectromechanical system technology, The appearance of micro mechanical processing technology puts forward sensor, especially force sensor, to a new development stage [1]. Microelectromechanical system (MEMS) is a interdisciplinary frontier research field which develops based on micro son technology. After decades of development, it has become a important technical fields of world. It refers to electronics, machinery, materials, physics, chemical, biology, medicine and so on many kinds of science and technology, and has wide application prospects. At present, about 600 units engaged in the development and production of MEMS working in the world, have developed out including miniature pressure sensor, acceleration sensors, micro ink-jet printing head, digital micro mirror display, hundreds of products, the and micro sensors accounts for a considerable proportion. Micro sensors is the new sensor which using microelectronics and micro mechanical processing technology to create. Compared with the traditional sensor, it has the advantages of small volume, light weight, low cost, low power consumption, high reliability, suitable for batch production, easy integration and realizing intelligent characteristic. Meanwhile, the characteristic dimensions in sub-micrometer range make it can do some function which traditional mechanical sensor can't function realize [2]. This paper summarizes the micro mechanical sensor which has already been realized in the domestic and foreign, especially the type, working principle, performance and the development direction.

\section{Micro MechanicAl Processing TeCHNOLOGY AND Micro MechanicAl ForCE SENSOR}

Micro mechanical processing technology is a processing technology of making micro mechanical components and structure for sensors, micro actuators and microelectromechanical systems. It develops based on the silicon flat technology, and is one of most important new technology of current sensor technology fields. Micro mechanical processing techniques are generally divided into body micro mechanical processing technology, surface micro mechanical processing technology and metal micro mechanical processing technology, including body micro mechanical processing technology is the first developed. Body micro mechanical processing technology use various corrosion technology to process on silicon ontology materials, in order to make various microstructures. This kind of micro mechanical processing technology mainly deposited various film materials (including electroplating) on surface of silicon. Through using photolithography, corrosion and so on processing means on the surface film to process all sorts of micro mechanical structure. Many micro mechanical processing technologies developed according to micro mechanical actuators, but the surface micro mechanical processing technology has also been applied in micro mechanical force sensor, and became another powerful means of the micro mechanical force sensor development. In all kinds of force sensor, in addition to force measurement weighing transducer, micro mechanization have become the main development direction: micro mechanical pressure sensor has developed into the industry, become mainstream product of pressure sensor and micro acceleration sensor has already been produced. Micro 
electron-mechanical gyroscope research has also matured day by day; the product has already been vividly portrayed.

\section{The Present Situation Of Micro SEnsors}

Many units at home and abroad has already been adopted micro mechanical processing technology to develop all kinds of micro sensors research and got gratifying progress, and these research works involve array tactile sensor, resonant force sensor, miniature acceleration sensor, vacuum microelectronics sensor etc. This article will introduce micro mechanical force sensor research.

Now the most widely applied micro mechanical pressure sensor is silicon piezoresistive pressure sensor. Piezoresistive pressure sensor appeared in the 1960s, in the 1970s after micro mechanical processing technology made silicon cup batch production, the production efficiency of piezoresistive pressure sensor is high and cost is low. So it offers condition to explore the many new fields of application, and in the 80s made pressure sensor became the first batch production of micro machine can sensors.

Due to its extensive use of pressure sensor in industrial technology, people on the importance of the development of micro mechanical pressure sensor is still the spare no effort, these developments mainly for [2] .

\section{A. High sensitive pressure sensor}

Early pressure sensors which were processed with mechanical grinding, due to silicon membrane is difficult to be done. Sensitivity is not high, the lowest range kpa (about $100 \mathrm{kpa}$ equals 1 atmosphere). In adopting micro mechanical processing technology, silicon membrane thinned to dozens of $\mathrm{m}$, minimum range reduced to dozens of $\mathrm{kpa}$. For further thinning silicon membrane thickness, appear linear significantly poor. So the emergence of many 80 micro mechanical processing technology to improve silicon membrane structure design, these structure is to realize the stress concentration to obtain higher sensitivity, on the other hand is to reduce the membrane to improve linear displacement. In many silicon membrane in the microstructure of the two most typicality. One is the end of the decade, ents 70 falk (Endevco) company introduces double island a membrane structure. Another is the author in the 1970s 80 introduced the micro mechanical beam in silicon membrane structure, formed beam a membrane structure or beam an island a membrane structure. Adopt beam structure silicon membrane is developed in recent years international pressure sensor mainstream micro range. The international first micro pressure sensor, its range has reached $1 \mathrm{kpa}$. Further improved, and will encounter more difficult, but still possible.

\section{B. High-temperature working pressure sensor}

General micro mechanical pressure sensor in the perturbation high temperature $20{ }^{\circ} \mathrm{C}$ about 1 . In engine pressure measurement, such as oil pressure measurement high temperature environment cannot work. Since the 1990s, people always 80 with SOS pressure sensors for temperature measurement. SOS is the abbreviation of sapphire epitaxial on silicon. For making the sensors, should be in sapphire base heteroepitaxy about $1 \mathrm{~m}$ thick monocrystalline silicon thin film, then etching, due to force output sensitive resistance between sensitization of insulation resistance is medium, there is no leakage problem, so the highest working temperature can achieve $400 \mathrm{U}$ around. Because sapphire substrates unable to micro mechanical processing, so this kind of pressure sensor making method will stay on the mechanical processing level. Not only processing efficiency is low, the sensitivity also do not high device, limiting its application scope.

\section{High precision pressure sensor}

General piezoresistive pressure sensor precision can reach about 0.1 , long-term stability in 0.2 / six months or so. To further improve the accuracy, technically difficult. In micro mechanical technology development, people would turn after the mechanical properties using silicon to develop high-precision pressure sensor. This effort basically has two aspects, one aspect is made using the micro mechanical processing silicon capacitance structure pressure sensor, on the other hand is made from silicon micro mechanical processing, through the resonant structure resonance frequency changes caused by pressure measured pressure.

\section{Micro Mechanical Force Sensor Application PROSPECT}

Angular velocity sensor is also commonly called gyro. The traditional gyro fundamental part is a high-speed rotating rotor, and use the principle of angular momentum conservation to determine the change. Angle Because the traditional gyro need very precise machining, the price is very expensive, so only in aircraft, ships, ships and missiles and other large systems just have applications. In fact, possible application field gyro than average people imagine much wants wide. Because the angular velocity and acceleration is same, also be characterization of one of the important parameters in the motion, so it is also extremely extensive application of the field. As long as the cost of gyro can come down and even poor precision, it will also have some huge market. For example, people in a hand-held camera on camera, because the handheld instability camera always have some slight rotation, the image quality will be serious becomes poor. If in the camera mount a gyro, using the gyro to detect the camera on tiny rolled and compensate for image signal. So video quality will improve greatly. Another example is car navigation on the application of the present automobile navigation system basically consists of two parts: a part is the global positioning system (GPS), and another part by a local positioning system provides short time navigation. The latter mainly in GPS work interval or car in the large building within the shaded area or tunnel provide some short-range navigation information. In such a local positioning system used in its accuracy requirements gyro, but not high. Other applications also much, like robots, artificial limbs, itactical missile even toys. Therefore, since the end of the 80 ,the international micro electron-mechanical gyroscope study more and more. These studies supported by many for the military, coupled with very high, so study difficult articles published less. But its progress is very 
compelling. Due to the micro mechanical processing technology is difficult to processing high-speed rotor, such a complex structure, so actually all present micro electronmechanical gyroscope design have abandoned the traditional gyro with suitable for rotor structures with micro mechanical processing square-ring vibrator. Micro electron-mechanical gyroscope vibrator type than pressure sensor or principle of acceleration sensor is much more complex, structural design also than pressure sensor or acceleration sensors is more complex and diverse .

\section{CONCLUSION}

Today, our product and its industrialization level still have a big gap compared with foreign developed, and the development of sensor technology is in the key stage of transformation and upgrading. Big demand of sensor, fast speed of demand growth, due to the domestic development of sensors behind the increase in demand, most of the domestic market, especially high-end market occupied by foreign, domestic sensor occupied low technical content, low quality requirements, low profit point market! Face the competition of the international market, our country sensor industry is in very adverse position, even in some areas appeared to exist crisis, therefore, we should seize opportunity, meet challenge, adhere to the road of combination technology with industry, strengthen the development of independent intellectual property rights new sensor, acceleration of existing scientific research achievements transformation and industrialization, rapid enhance the global market share of domestic sensors, is a urgent moment of our sensor industrial development, is also the only way which our sensing technology stands in the advanced level in the world

MEMS technology processing production with the microstructure of the sensor has the miniaturization, integration, array change, intelligent, low power consumption, low cost, high reliability and easy to batch production, realizing multicast many advantages, such as parameter examination by all countries' researchers' attention. Despite the current development of sensors have some shortcomings, such as sensitivity low, working temperature area is narrow, the accuracy is not high. But, as the researchers of thorough research, in the near future there will be more structure update, performance more excellent practical sensor published.

\section{REFERENCES}

[1] Goran Stemme.Micro Fluid Sensors and Actuators[C].Sixth International Symposium on Micro Machine and Human Science, 1995 .

[2] A. Chandrakasan et al., "Design considerations for distributed microsensor systems" [J]. Custom Integrated Circuits Conference (CICC),pp. 279-286, May 1999.

[3] Jeroschewski, P., Steuckart, C. \& Kühl, M. (1996) An amperometric microsensor for the determination of $\mathrm{H} 2 \mathrm{~S}$ in aquatic environments[M] Analytical Chemistry.

[4] J. BORUM, etc.The potential role of plant oxygen and sulphide dynamics in die-off events of the tropical seagrass, Thalassia testudinum[J].Journal ofEcology,2005.
[5] M.J. Vellekoop, G.W. Lubking, P.M. Sarro, and A. Venema. Integrated-circuit-compatible design and technology of acousticwave-based microsensor[J]s. Sensors and Actuators A (Physical), A44(3):249 63, September 1994.

[6] Stéphane MALLAT. A Wavelet Tour of Signal Processing[M]. BeiJing : China Machine Press,2002.

[7] S.Zhang et al.The Research of Mixed Programming Auto-Focus Based On Image Processing[J].ICICA 2010, PartI,CCIS105,PP.217225,2010 .

[8] S. Zhang, G. Jin, J. Xiao, S. Li, Y.P. Qin, J.H. Liu, T. An and W.F. Zhong.Generalized Constraint Neural Network Model System Parameter Identification[J].Advanced Materials Research Vols. 143144 ,pp 1207-1212,2011

[9] Schroeder W,Martin K, Lorensen B. The visualization toolKit an objectoriented approach to $3 \mathrm{D}$ graphics $[\mathrm{M}]$. 3th ed. New Jersey: Prentice-Hall , 2002: 241- 243.

[10] Wearable Technology, Special Issue of the IEEE Engineering in Medicine and Biology Magazine, vol. 22, 2003.

[11] C. S. Ikehara, E. Biagioni, and M. E. Crosby, Ad-hoc Wireless Body Area Network for Augmented Cognition Sensors In Foundations of Augmented Cognition[J], 2007

[12] D. Konstantas, A.T. van Halteren, R.G.A. Bults, K.E Wac, V.M. Jones and I.A. Widya. Body Area Networks for Ambulant Patient Monitoring Over Next Generation Public Wireless Networks[J]. In: 14th IST Mobile and Wireless Communications Summit, 2004

[13] J.Y. Khan, M.R. Yuce and F. Karami. Performance Evaluation of a Wireless Body Area Sensor Network for Remote Patient Monitoring $[\mathrm{J}]$. Proc 30th IEEE International Conference on Engineering in Medicine and Biology Society (EMBS), 2008

[14] M. Sukor, S. Ariffin, N. Fisal, S.K.S. Yusof, and A. Abdallah. Performance Study of wireless Body Area Network in a Medical Environment.Proc[J]. 2nd Asia International Conference on Modeling \& Simulation(AICMS), 2008

[15] A. Donelli, J.R.C. Jansen, B. Hoeksel, P. Pedeferri, R. Hanania, J. Bovelander, et al.,Performance of a real-time dicrotic notch detection and predication algorithm in arrhythmic body aortic pressure signals[J]. Journal of Clinical Monitoring and Computing 17 (2002) $182-185$.

[16] W. Zong, T. Hedlt, G.B. Moody, R.G. Mark, An open-source algorithm to detect nset of arterial blood pressure pulses[J].Computers in Cardiology 30 (2003) 259-262.

[17] Schroeder W,Martin K, Lorensen B. The visualization toolKit an objectoriented approach to $3 \mathrm{D}$ graphics $[\mathrm{M}]$. 3th ed. New Jersey: Prentice-Hall , 2002: 241- 243.

[18] Wearable Technology, Special Issue of the IEEE Engineering in Medicine and Biology Magazine, vol. 22, 2003.

[19] C. S. Ikehara, E. Biagioni, and M. E. Crosby, Ad-hoc Wireless Body Area Network for Augmented Cognition Sensors In Foundations of Augmented Cognition, 2007

[20] D. Konstantas, A.T. van Halteren, R.G.A. Bults, K.E Wac, V.M. Jones and I.A. Widya. Body Area Networks for Ambulant Patient Monitoring Over Next Generation Public Wireless Networks. In: 14th IST Mobile and Wireless Communications Summit, 2004

[21] J.Y. Khan, M.R. Yuce and F. Karami. Performance Evaluation of a Wireless Body Area Sensor Network for Remote Patient Monitoring. Proc 30th IEEE International Conference on Engineering in Medicine and Biology Society (EMBS), 2008

[22] M. Sukor, S. Ariffin, N. Fisal, S.K.S. Yusof, and A. Abdallah. Performance Study of wireless Body Area Network in a Medical Environment.Proc. 2nd Asia International Conference on Modeling \& Simulation(AICMS), 2008

[23] A. Donelli, J.R.C. Jansen, B. Hoeksel, P. Pedeferri, R. Hanania, J. Bovelander, et al.,Performance of a real-time dicrotic notch detection and predication algorithm in arrhythmic body aortic pressure signals, Journal of Clinical Monitoring and Computing 17 (2002) 182-185. 
[24] W. Zong, T. Hedlt, G.B. Moody, R.G. Mark, An open-source algorithm to detect nset of arterial blood pressure pulses, Computers in Cardiology 30 (2003) 259-262.
[25] M. Aboy, J. McNames, T. Thong, D. Tsunami, M.S. Ellenby, B. Goldstein, An automatic beat detection algorithm for pressure signals, IEEE Transactions on Biomedical Engineering 52 (2005) 1662-1670. 